\title{
Fluoro-2-deoxy-D-glucose positron emission tomography/computed tomography imaging in the investigation of Lambert-Eaton myasthenic syndrome
}

FDG-PET/CT na investigação da síndrome miastênica de Lambert-Eaton

Vera L. Braatz', Cláudia S. K. Kay', Paulo J. Lorenzoni, Vinicius B. Ludwig², Milton M. Machota Junior³, Sergio O. Ioshii ${ }^{3}$ Rosana H. Scola' , Lineu C. Werneck ${ }^{1}$

A 56-year-old smoker woman presented with progressive gait disturbance, dysarthria, cerebellar ataxia, limb weakness, hyporreflexia, and weight loss. Electromyography was compatible with Lambert-Eaton myasthenic syndrome (LEMS). Serum anti-P/Q-type voltage-gated calcium channel antibody was detectable. Thoracic computed tomography (CT-thorax) showed a non-specific mediastinal mass. Whole-body [(18)F]fluoro-2-deoxy-D-glucose positron emission tomography/computed tomography (FDG$\mathrm{PET} / \mathrm{CT})$ ] imaging revealed abnormality in the same topography (Fig $1 \mathrm{~A}$ and B). Mediastinal biopsy showed lymph node infiltrated by small-cell lung cancer (SCLC) (Fig C).
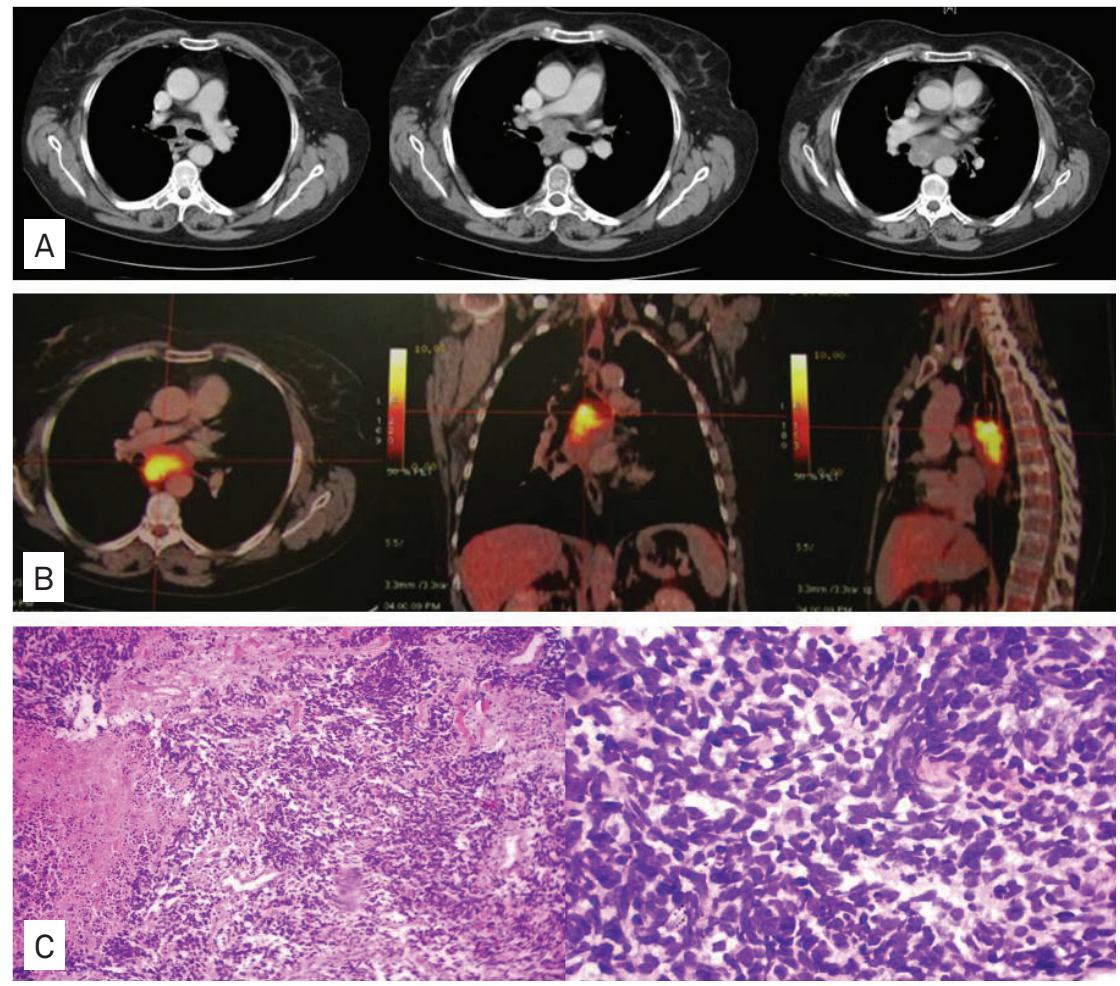

Fig 1. (A) Thoracic computed tomography showed posterior mediastinal mass. (B) [(18)F]fluoro-2-deoxy-D-glucose positron emission tomography/computed tomography imaging revealed area of abnormal FDG accumulation in posterior mediastinal topography. (C) Histopathology of the mediastinal mass biopsy showed lymph node infiltrated by poorly differentiated malignant neoplasm (HE, 100×, 400x), the imunophenotyping of which was consistent with small-cell lung cancer.

\footnotetext{
${ }^{1}$ Neurology Division, Internal Medicine Department, Hospital de Clínicas, Universidade Federal do Paraná (UFPR), Curitiba PR, Brazil; ${ }^{2}$ Radiology Division, Centro de Diagnóstico por Imagem (CETAC), Curitiba PR, Brazil; 
LEMS, especially the classical forms with positive antibody, should be extensively investigated to locate the tumor site ${ }^{1,2}$. Additional tests such as FDG-PET are complementary tools of great value when conventional methods are inconclusive ${ }^{1,3}$. Recommendation from European Federation of Neurological Societies is screen for SCLC by CT-thorax, followed by FDG-PET or integrated FDG-PET/CT ${ }^{1}$.

\section{References}

1. Titulaer MJ, Soffettib R, Dalmauc J, et al. Screening for tumours in paraneoplastic syndromes: report of an EFNS Task Force. Eur J Neurol 2011;18:19-27.

2. Lorenzoni PJ, Scola RH, Kay CS, Parolin SF, Werneck LC. Non-paraneoplastic Lambert-Eaton myasthenic syndrome: a brief review of 10 cases. Arq Neuropsiquiatr 2010;68:849-854.
3.

Younes-Mhenni S, Janier MF, Cinotti L, et al. FDG-PET improves tumour detection in patients with paraneoplastic neurological syndromes. Brain 2004;127:2331-2338. 